\title{
The effect of hydrodynamic conditions on the monogastric-like in vitro digestion of maize flours dried at different temperatures
}

\author{
François Huart $^{\mathrm{a}, \mathrm{b}, *}$, Nathalie Peclers ${ }^{\mathrm{b}}$, François Béra ${ }^{\mathrm{a}}$, Yves Beckers ${ }^{\mathrm{b}}$, Paul Malumba ${ }^{\mathrm{c}}$ \\ ${ }^{\text {a }}$ University of Liège, Gembloux Agro-Bio Tech, Food Engineering Laboratory, Passage des Déportés, 2, B-5030, Gembloux, Belgium \\ ${ }^{\mathrm{b}}$ University of Liège, Gembloux Agro-Bio Tech, Precision Livestock and Nutrition, Passage des Déportés, 2, B-5030, Gembloux, Belgium \\ ${ }^{\mathrm{c}}$ Care FoodIsLife, Terra Teaching and Research Centre, University of Liège, Gembloux Agro-Bio Tech, Avenue de la Faculté 2B, B-5030, Gembloux, Belgium
}

\section{A R T I C L E I N F O}

\section{Keywords:}

Mixing

Maize

Drying

Digestion

Sedimentation

Hydrodynamic

\begin{abstract}
A B S T R A C T
The effect of hydrodynamic conditions on the in vitro digestion of two maize varieties (flint-dent and flint maize), dried at different temperatures $\left(54^{\circ} \mathrm{C}, 90^{\circ} \mathrm{C}\right.$ or $130{ }^{\circ} \mathrm{C}$ ), was assessed. During the digestion assay, maize flours were mixed using either gentle agitation (a shaking bath) or rotational agitation at four different speeds. Increasing rotational agitation gradually increased the digestibility of the in vitro dry matter (IVDMD) and of starch (IVSD) by 15 and 20\%, respectively, and also affected the rate of starch amylolysis. The increase in digestion with the mixing rate was modulated by the thermal history suffered by the feedstuff materials. The variability introduced by flour thermal histories makes it difficult to compare the digestibility of such materials of unknown origin without the standardization of mixing procedures. Flour thermal history also results in different rheological properties of samples, with potential implications for enzymatic digestion that current static in vitro protocols are not able to reproduce. In order to improve the predictive quality of static in vitro models and for a reliable comparison of the digestibility of foods and feedstuffs, hydrodynamic and mixing procedures need to be optimized and standardized.
\end{abstract}

\section{Introduction}

The digestion of food involves several stages in different parts of the gastro-intestinal tract (GIT) of the consumer. In order to assess the feeding value of foods and feedstuffs, in vitro digestion protocols that mimic phenomena occurring inside the GIT have been developed and have received increasing attention during recent decades. These protocols avoid the use of animal experimentation, which is time consuming and expensive, and also raises important ethical issues.

The prediction of the nutritional value of feedstuffs through these in vitro digestion protocols appears to be challenging for the scientific community because of the complexity of the digestion process (Bohn et al., 2018). During their passage through the GIT, solid particles are moistened and are exposed to mechanical forces and enzyme digestion. The peristaltic waves of the GIT involve adequate mixing of food with enzymes and a reduction in food particle size, thereby increasing the available surface area for enzyme digestion (Kong \& Singh, 2010), and movement in a retropulsive flow pattern (Van Wey \& Shorten, 2014). Thus, the peristaltic waves appear to be fundamental in the digestion process, along with some of the intrinsic characteristics of digested food (structure, particle size, composition), which may be modulated by thermal processing (Odjo, Béra, Beckers, Foucart, \& Malumba, 2018).

There are remarkably few experimental studies that describe the effect of mechanical forces applied to the food bolus during the in vitro digestion process of monogastrics. Since the hydrodynamic parameters applied during in vitro protocols may affect the physical structure of feedstuffs, as well as their enzyme susceptibility, it is important to assess the effect of such parameters on the kinetic of digestion. In most static in vitro digestion models, a major emphasis has been placed on optimizing enzymatic concentration, $\mathrm{pH}$ conditions or incubation time, and there has been less emphasis on the mixing method applied. This has led to the application of a huge diversity of mixing methods (manual agitation, shaking water bath with tubes maintained vertically or horizontally, magnetic stirring, ...), making comparison between studies very difficult (Woolnough, Monro, Brennan, \& Bird, 2008). In some other published protocols, the mixing procedures are not fully described or are ambiguous and left to the interpretation of the reader (Minekus et al., 2014; Rozan et al., 1997; Tervilä-Wilo et al., 1996).

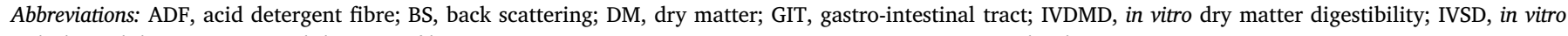
starch digestibility; NDF, neutral detergent fibre; RPM, rotations per minute; T, transmission; WBC, water binding capacity

* Corresponding author. Laboratory of Food Process Engineering, University of Liège, Gembloux Agro-Bio Tech, Passage des Déportés 2, 5030, Gembloux, Belgium.

E-mail address: fran-h@msn.com (F. Huart).
} 
Several results obtained using static in vitro digestion protocols are not well correlated with digestion protocols performed in vivo (Berti, Riso, Monti, \& Porrini, 2004; Brand-Miller \& Holt, 2004; Huart et al., 2018). The low predictive quality of in vitro protocols may result from the oversimplification of digestion phenomena, as well as from the application of inadequate food bolus agitation modalities (Alegría, Garcia-Llatas, \& Cilla, 2015). Questions therefore arise concerning the suitability of mixing rates applied during in vitro protocols and their influence on the rate and the extent of food digestion (Woolnough et al., 2008), as well as in terms of their predictive value regarding the in vivo experience of consumers. Furthermore, the mixing rate applied to the food bolus during GIT digestion may influence the kinetic of digestion. Understanding the effect of hydrodynamic regimes on the kinetic of digestion, especially that of glucose-based compounds, seems fundamental to the implementation of accurate in vitro digestion protocols, and is also important in highlighting some of the mechanisms associated with the physiology of glucose digestion in monogastrics.

The aim of this study was to assess the effect of various hydrodynamic regimes on the digestibility of two maize varieties dried at different temperatures during an in vitro pepsin-pancreatic digestion scheme.

\section{Material and methods}

\subsection{Feedstuffs used}

Two maize varieties [a flint-dent maize (Var I) and a flint maize (Var II)] were field grown and harvested at the same time, at 34.5 and $33.7 \%$ of moisture content. Samples of both the maize varieties were dried at $54{ }^{\circ} \mathrm{C}$ for $270 \mathrm{~min}$, at $90{ }^{\circ} \mathrm{C}$ for $90 \mathrm{~min}$ and at $130{ }^{\circ} \mathrm{C}$ for $40 \mathrm{~min}$, using a fluidized bed drier, as described by Janas, Boutry, Malumba, Vander Elst, and Béra (2010). Each of these six samples was then milled using an IKA M20 (Germany) grinder and sieved through a $500 \mathrm{~mm}$ sieve mesh. Particle size distribution of the resulting maize flours was determined at room temperature using a laser scattering analyser (Malvern Instruments, Ltd., UK), equipped with a Mastersizer 2000 (Ver. 5.22) data analysis station. Particle size was defined in terms of the 10 th percentile $[\mathrm{d}(0.1)]$, median $[\mathrm{d}(0.5)]$ and 90 th percentile $[\mathrm{d}$ (0.9)].

In order to characterize their composition, the dry matter (DM) of the maize flours was determined using AOAC (1990) methods 967.03. Maize flour ash content was determined using AOAC (1990) methods 942.05. Flour starch content was quantified using Ewers' polarimetric method (ISO 10520:1997). Protein content was determined using the Dumas method (ISO 16634-1:2008). Levels of neutral detergent fibre (NDF) and acid detergent fibre (ADF) were determined using an ANKOM-Fiber Analyzer (ANKOM-Technology, Fairport, NY), according to the method of Van Soest, Robertson, and Lewis (1991). NDF and ADF content were corrected for ash content, and the presence of NDF was determined in the maize using thermostable amylase (Termamyl ${ }^{\circledR}$, Novo Nordisk, Bagsværd, Denmark). Lipid content was determined using a Soxhlet extractor (method 920.29; AOAC, 1990). All analyses were duplicated.

\subsection{Monogastric-like in vitro digestion protocols applied}

A three-step in vitro digestion protocol, previously described by Huart et al. (2018), was used with slight modifications. In order to simulate the digestion phase, $0.4 \mathrm{~g}$ of each maize flour sample was weighed in a $15 \mathrm{~mL}$ polypropylene tube. Two blanks were included in each of the series. Sodium acetate $(4 \mathrm{ml} 0.05 \mathrm{~mol} / \mathrm{L}, \mathrm{pH} 5.4)$ and acetic acid $(50 \mu \mathrm{L}, 1 \mathrm{~mol} / \mathrm{L})$ were added into the tubes and the tubes placed in a water bath for $30 \mathrm{~min}$ at $40{ }^{\circ} \mathrm{C}$ under agitation. After this step, chloramphenicol solution ( $40 \mu \mathrm{L}, 0.5 \mathrm{~g} / 100 \mathrm{~mL}$ of ethanol) and $\mathrm{HCl}$ solution (1.23 mL, $0.2 \mathrm{~mol} / \mathrm{L})$ were added to adjust the $\mathrm{pH}$ to $3 \pm 0.2$. Fresh pepsin solution $(0.8 \mathrm{~mL}, 25 \mathrm{~g} / \mathrm{L}$ of $0.05 \mathrm{~mol} / \mathrm{L} \mathrm{HCl})$, prepared from pepsin powder (EC 3.4.23.1; from porcine gastric mucosa; > 250 $\mathrm{U} / \mathrm{mg}$ of solid powder, P7000; Sigma-Aldrich, Germany) was then added and the tubes were placed in a water bath for $45 \mathrm{~min}$ at $40{ }^{\circ} \mathrm{C}$ under agitation. After the gastric phase, $6 \mathrm{~mL}$ of sodium monohydrogenocarbonate $0.2 \mathrm{~mol} / \mathrm{L}$ were added. The $\mathrm{pH}$ was then adjusted to $6.8 \pm 0.2$ using a $0.1 \mathrm{~mol} / \mathrm{L} \mathrm{HCl}$ or a $0.1 \mathrm{~mol} / \mathrm{L} \mathrm{NaOH}$ solution. Next, $0.29 \mathrm{~mL}$ of fresh pancreatin solution (prepared from pancreatin 8xUSP/g of solid powder, P7545; Sigma-Aldrich, Germany; $100 \mathrm{~g} / \mathrm{L}$ of phosphate buffer $0.2 \mathrm{~mol} / \mathrm{L}, \mathrm{pH} 6.8$; undissolved tissue material having been removed after centrifugation at $3220 \mathrm{x}$ g) was added and the tubes were incubated at $40{ }^{\circ} \mathrm{C}$, in the same water bath, for a period of $2 \mathrm{~h}$ under agitation.

Finally, the supernatants and the undigested fractions were separated after centrifugation at $3220 \mathrm{x}$ g for a period of $10 \mathrm{~min}$. The undigested fractions recovered were washed with a $10 \mathrm{~mL}$ solution of acetone and ethanol, dried at $60{ }^{\circ} \mathrm{C}$ in order to attain a constant weight $(72 \mathrm{~h})$ and then weighed. The supernatants were stored at $-18^{\circ} \mathrm{C}$ until analysis.

The in vitro dry matter digestibility (IVDMD) was calculated as follows:

$\operatorname{IVDMD}(\%)=$ DM maize - DM undigested maize $/$ DM maize $\times 100$

where DM maize is the dry matter of maize flour weighed before the in vitro digestion and DM undigested maize is the dry matter of the undigested fraction after drying at $60{ }^{\circ} \mathrm{C}$ for a period of $72 \mathrm{~h}$. Five measurements were performed for each treatment.

The in vitro digestibility of starch was determined according to the following equation:

$\operatorname{IVSD}(\%)$

$=($ Starch in the supernatant $(\mathrm{g}))$

$($ Starch in the sample of flour before hydrolysis $(\mathrm{g})) \times 100$

\subsection{Hydrodynamic regimes assessed}

In order to assess the effect of the hydrodynamic regime applied during the digestion protocol, a gentle agitation in a shaking water bath and rotational agitation with four different speeds of rotation were compared. During the gentle agitation, tubes were maintained vertically and agitation was performed by a shaking bath (shaking frequency of 120 RPM). Moreover, manual agitation was applied every $15 \mathrm{~min}$ during pepsin incubation and every 30 min during pancreatin incubation. Rotational agitation was performed with a Multi-Function Rotator PTR-60 (Grant-Bio) throughout the digestion process. The tubes on the agitator platform were placed in a polycarbonate water bath, equipped with a cover to maintain a constant temperature. Water was kept at $40{ }^{\circ} \mathrm{C}$ by means of a circulating water bath (Polystat 71, Fisher Scientific), set at $41.5^{\circ} \mathrm{C}$. The effect of rotational agitation on the in vitro digestibility of the maize flour samples was assessed at 1, 3, 5 and 10 rotations per minute (RPM).

\subsection{Study of the starch digestion kinetic}

The starch digestion kinetic was studied under gentle agitation in a shaking water bath and in the water bath with rotational agitation at 10 RPM, using different incubation times at the pancreatic stage of digestion. For each point of this kinetic, two tubes were withdrawn from the bath after $0,10,20,30,60$ and $120 \mathrm{~min}$ of incubation time. For each incubation time, a blank was removed at the same time. Tubes were immediately cooled in an ice bath and then centrifuged at $3220 \mathrm{x}$ $\mathrm{g}$ for $10 \mathrm{~min}$. The supernatants were stored at $-18{ }^{\circ} \mathrm{C}$ pending further analysis. Residual undigested fractions were dried at $60{ }^{\circ} \mathrm{C}$ until constant weight.

The saccharide content of the supernatants was determined using a glucose oxidase peroxidase assay kit from Megazyme (K-GLUC 09/14, 
Megazyme, Ireland), as described by Odjo, Béra, Jacquet, Richel, and Malumba (2016).

\subsection{Modelling}

Experimental data from the starch digestion kinetic were fitted to a modified pseudo first-order kinetic model, as described by Goni, GarciaAlonso, and Saura-Calixto (1997):

$C_{t}=C_{0}+\left(C_{\infty}-C_{0}\right) \times\left(1-\exp \left(-k_{s} t\right)\right)$

where $\mathrm{C}_{\mathrm{t}}$ is the starch digestibility (\%) at time $\mathrm{t}, \mathrm{C}_{0}$ is the starch digestibility (\%) at the beginning of the intestinal step of digestion $\left(\mathrm{t}_{0}\right)$, $\mathrm{C}_{\infty}$ is the digestibility (\%) at the asymptotic point, $\mathrm{k}_{\mathrm{s}}$ is the constant rate $\left(\mathrm{min}^{-1}\right)$ digestibility and $\mathrm{t}$ is the incubation time ( $\mathrm{min}$ ).

A pseudo-first order-like model was used to fit the variation of DM digestibility (at the end of the pancreatic digestion phase) under different speeds of rotational agitation (from 0 to 10 RPM):

$D_{S}=D_{S 0}+\left(D_{\infty}-D_{S 0}\right) \times\left(1-\exp \left(-k_{r} S\right)\right)$

Where $\mathrm{D}_{\mathrm{S}}$ is the dry matter digestibility (\%) at the end of the pancreatic digestion phase at a given rotational speed, $\mathrm{D}_{\mathrm{S} 0}$ is the dry matter digestibility (\%) at the end of the pancreatic digestion phase under gentle agitation (0 RPM), $\mathrm{D}_{\infty}$ is the dry matter digestibility (\%) at the asymptotic point, $k_{r}$ is the rate constant (min/rotation) and $S$ is the rotational speed (rotation/min).

The Microsoft Excel Solver was used to determine the parameters of the model in order to minimize the root mean square error between experimental and predicted values.

The root mean square error (RMSE) was calculated as follows:

$R M S E=\sqrt{\sum_{i=1}^{n}\left(y_{i \exp }-y_{i \text { calc }}\right)^{2} / n}$

where $y_{i} \exp$ and $y_{i}$ calc are, respectively, the experimental data and predicted data calculated with the pseudo first-order model and $n$ is the number of experimental points.

\subsection{Water binding capacity}

Approximately $0.26 \mathrm{~g}$ of maize flour was weighed in triplicate in a $15 \mathrm{~mL}$ centrifuge tube, and $10 \mathrm{~mL}$ of distilled water was added. These tubes were vortexed and placed in a shaking water bath at $40{ }^{\circ} \mathrm{C}$ for $30 \mathrm{~min}$. Samples were then centrifuged at $3100 \mathrm{x} \mathrm{g}$ for $30 \mathrm{~min}$. The supernatant was poured out from the tubes and the wet residues were weighed. The number of grams of water held by each maize flour sample was determined. Measurements were performed in triplicate and the results were presented as a mean with standard deviation.

\subsection{Maize flour particle sedimentation}

The stability of the flour in solution was analysed with an optical analyser (Turbiscan MA 2000). This device enables the optical characterization of any type of dispersion and detects particle migration much earlier than the operator's naked eye (Mengual, 1999). Maize flours were mixed in test tubes with water in concentrations similar to those presumed to be present in the digestion solution at the intestinal step. After homogenization, the tubes were immediately placed in the optical analyser and data were recorded at 1-min intervals for $20 \mathrm{~min}$ at room temperature. The optical analyser is composed of a head that moves up and down along the glass tubes, and is equipped with a pulsed near-infrared light source $(\lambda=850 \mathrm{~nm})$. Two detectors-a transmission (T) detector and a back scattering (BS) detector-receive, respectively, light going across the sample ( $0^{\circ}$ from the incident beam) and the light scattered backward at $135^{\circ}$ from the incident beam. The sample is scanned every $40 \mu \mathrm{m}$ from the bottom to the top. All measurements were carried out in duplicate.

\subsection{Rheology parameters}

The apparent viscosity of the maize flour suspensions was assessed using a Anton Paar Physica mcr 301 rheometer (Anton Paar, Germany), fitted with an electrical heated cylinder system.

Approximately $17.8 \mathrm{~g}$ of the slurry from the intestinal step before the start of incubation were collected and placed in a stirrer cell type ST24-2D/2V/2V (Anton Paar, Germany). Flow behaviour measurements were performed to an increase-decrease screw speed cycle, varying experimentally from 0.1 to $400 \mathrm{~s}^{-1}$ for $10 \mathrm{~min}$ at $40{ }^{\circ} \mathrm{C}$. Only descending shear data were presented.

In order to compare the apparent viscosity of the slurry from in vitro digestion with the viscosity of intestinal content as may be observed in vivo, maize flour suspensions of $25 \% \mathrm{~W} / \mathrm{W}$ were also prepared and the apparent viscosity was measured for the 6 samples using the same procedure. Solid concentrations were chosen to represent the dry matter of the intestinal content of poultry, as observed in several studies (Günal, Yaşar, \& Forbes, 2004; Svihus, Herstad, Newman, \& Newman, 1997; Takahashi, Goto, \& Sakata, 2004). Wale).

Collected data were fitted with the power law model (Ostwald De

$\tau=K \gamma^{n}$

where $\tau$ is the shear stress (Pa), $\mathrm{K}$ is the consistency index $\left(\mathrm{Pa} . \mathrm{s}^{\mathrm{n}}\right), \gamma$ is the shear rate $(1 / \mathrm{s})$ and $n$ is the flow behaviour index.

\section{Results and discussion}

The effect of hydrodynamic condition on either the in vitro digestibility of maize dried at different temperatures as well as the influence of such hydrodynamic conditions on the kinetic of maize flour amylolysis were studied. The main goal was to understand the origin of the weak correlations between the results observed using static in vitro digestion protocols and the digestion observed in animals and to understand the origin of the variability of results observed between in vitro procedures performed in different laboratories. The results of these studies are presented and discussed in the following paragraphs.

\subsection{Effect of hydrodynamic conditions (rotational speed) on the in vitro digestibility of maize dried at different temperatures}

Statistically, no significant difference could be inferred regarding the initial chemical composition of the two maize varieties used or for samples of the same variety dried at different temperatures. The starch content, crude protein content and lipid and fibre content of the six treatments were found to be similar. The starch content, crude protein, lipids, NDF and ADF averaged 72\%, 7.5\%, 5.5\%, 10.7\% and 2.3\% of dry matter, respectively.

Fig. 1 shows the in vitro dry matter digestibility of maize flour (IVDMD) and of starch (IVSD), measured under gentle agitation (shaking bath) and rotational agitation at 10 RPM for the two maize varieties used. Compared with the digestion observed with gentle agitation, the high mixing rate applied with the rotational agitation improved considerably the IVDMD and IVSD for all samples (Fig. 1). The increase in IVDMD and IVSD reached $15 \%$ and $22 \%$, respectively, for both varieties. The increase in IVDMD could mainly be explained by the improvement of starch digestibility under rotational agitation (Fig. 1). It was assumed that the settling of particles within the solution greatly reduced the contact between enzymes and substrates under gentle agitation. Boisen and Fernández (1997) observed that sufficient agitation is required to allow efficient starch digestibility from starch-rich feedstuffs.

The digestibility of both maize flour and starch increased with the increasing drying temperature from $54{ }^{\circ} \mathrm{C}$ to $130{ }^{\circ} \mathrm{C}$, which is in agreement with the results of Odjo et al. (2018). The increase in IVDMD was found to be highly correlated with the digestibility of maize starch 

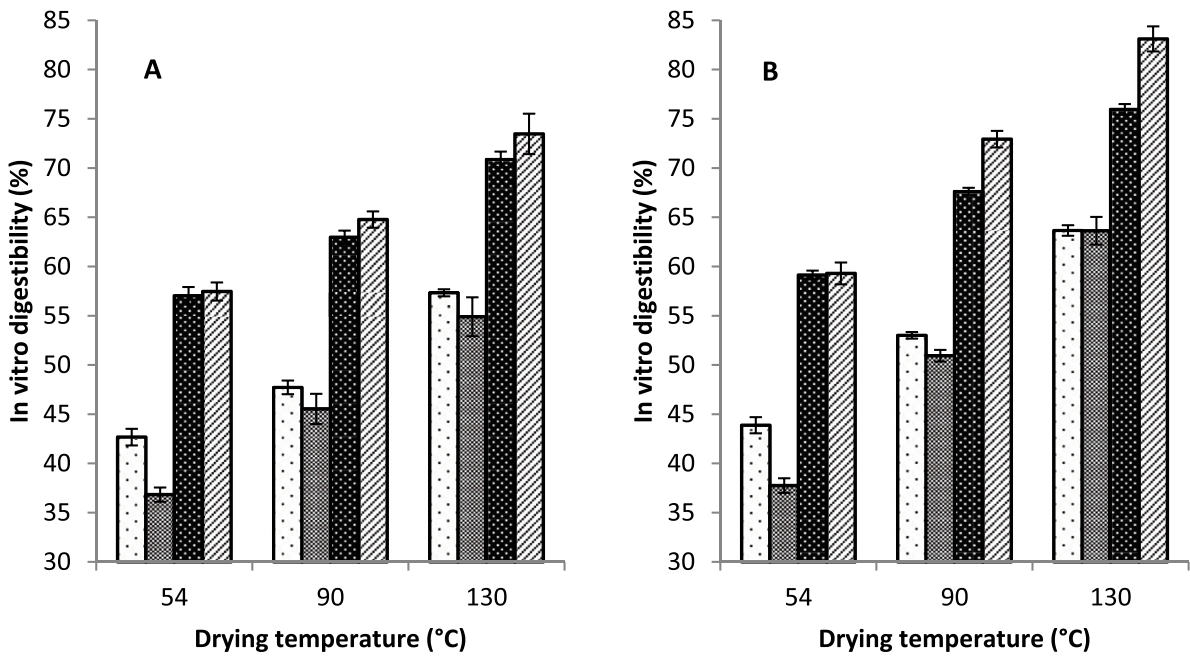

Fig. 1. In vitro dry matter and in vitro starch digestibility of maize flour samples measured under gentle agitation (shaking bath) and rotational agitation at 10 RPM for Var I (A) and II (B). Values are means \pm standard deviation $(\mathrm{n}=5)$. IVDMD shaking bath ( $\boldsymbol{\square})$; IVSD shaking bath (四); IVDMD at 10 RPM (田); IVSD at 10 RPM (四). $(\mathrm{r}=0.99)$. Such an increase in drying temperature is known to induce the partial gelatinization of starch granules and a collapse in their structure (Malumba et al., 2014). These structural modifications potentially improve the accessibility and diffusion of $\alpha$-amylase into the starch granules (Malumba et al., 2014). In the present study, the increase in starch and dry matter digestibility with increasing drying temperature was more pronounced for Var II, despite similar digestibility being observed at $54{ }^{\circ} \mathrm{C}$. It is likely that the pre-gelatinization process was enhanced in the Var II grain because of its vitreous endosperm.

In order to assess the particle sedimentation that may occur in a static regime, maize flours were mixed in glass tubes with water in the same concentration as in the solution at the intestinal step. The transmission (T) and back scattering (BS) signals were recorded with the optical analyser (Turbiscan MA 2000). The profiles observed after 0, 5 and 15 min are presented in Fig. 2. The high BS signal at initial time
$\left(\mathrm{T}_{0}\right)$ at the bottom of the tubes revealed a rapid sedimentation of maize flour before the start of the scan. The high BS signal observed simultaneously with the high T signal at the top was due to a secondary glass reflection. In these conditions, BS should be ignored (Lefeuvre, Y. EMEA Manager Formulaction, L'Union, France, personal communication 2011). The T signal at the top of the glass tubes progressively increased for each sample, suggesting a clarification process in this area because of the particle sedimentation. At the same time, it was observed that BS increased at the bottom of the test tubes. The fluctuation in BS and $\mathrm{T}$ showed that sedimentation continued over time.

The clarification front and the height of the sediment peak decreased with increasing drying temperature (Fig. 2). Sedimentation is a simple phenomenon, the rate of which depends on the size and density of the particles (Chauvierre, Labarre, Couvreur, \& Vauthier, 2004). In order to understand the differences in particle sedimentation of samples with a different thermal history, the particle size and the water binding
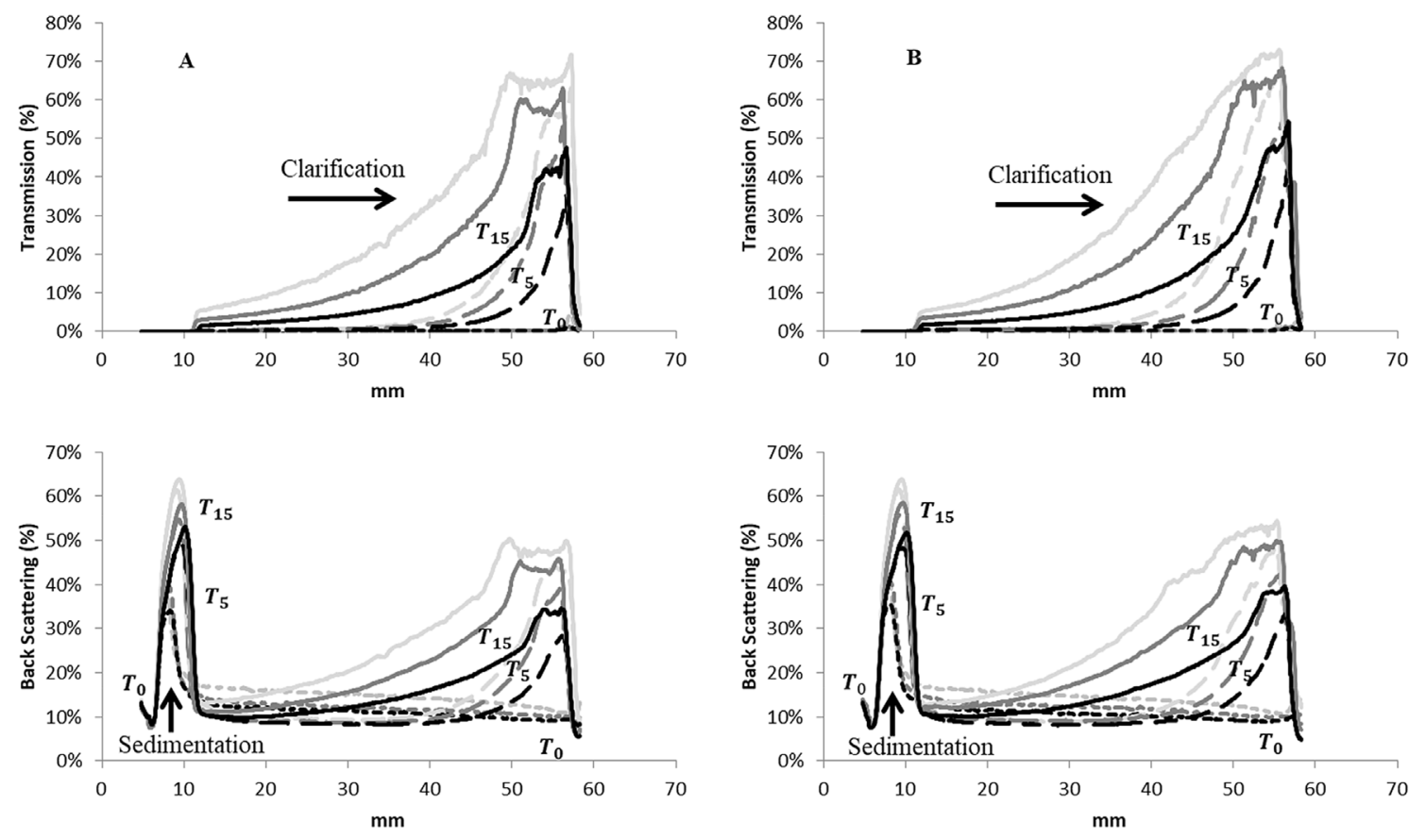

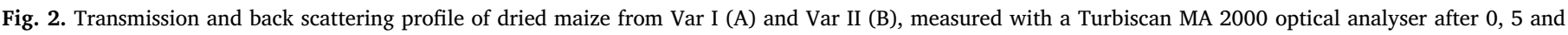

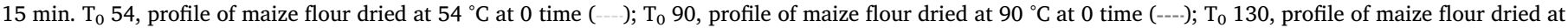

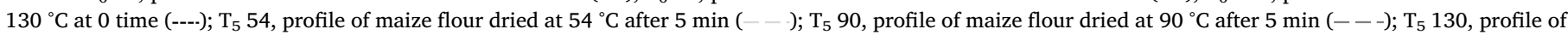

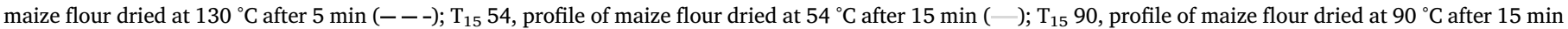
(-); $\mathrm{T}_{15} 130$, profile of maize flour dried at $130{ }^{\circ} \mathrm{C}$ after $15 \mathrm{~min}(-)$. 
Table 1

Particle size distribution and water binding capacity of the two maize varieties dried at $54{ }^{\circ} \mathrm{C}, 90^{\circ} \mathrm{C}$ and $130{ }^{\circ} \mathrm{C}$.

\begin{tabular}{llllll}
\hline $\begin{array}{l}\text { Maize } \\
\text { variety }\end{array}$ & $\begin{array}{l}\text { Drying } \\
\text { temperature }\end{array}$ & \multicolumn{2}{l}{ Granulometry $(\mu \mathrm{m})$} & \begin{tabular}{l} 
Water binding capacity \\
\cline { 3 - 6 }$(\mathrm{g}$ water/g DM)
\end{tabular} \\
\cline { 3 - 6 } & & $\begin{array}{l}\mathrm{d}(0.1) \\
(\mu \mathrm{m})\end{array}$ & $\begin{array}{l}\mathrm{d}(0.5) \\
(\mu \mathrm{m})\end{array}$ & $\begin{array}{l}\mathrm{d}(0.9) \\
(\mu \mathrm{m})\end{array}$ \\
\hline Var I & $54{ }^{\circ} \mathrm{C}$ & 26.6 & 157.9 & 447.9 & $1.25 \pm 0.004$ \\
& $90{ }^{\circ} \mathrm{C}$ & 26.3 & 193.9 & 467.4 & $1.51 \pm 0.040$ \\
& $130{ }^{\circ} \mathrm{C}$ & 28.4 & 186.6 & 439.6 & $1.85 \pm 0.024$ \\
\cline { 2 - 6 } Var II & $54{ }^{\circ} \mathrm{C}$ & 17.7 & 167.3 & 466.9 & $1.25 \pm 0.018$ \\
& $90{ }^{\circ} \mathrm{C}$ & 24.7 & 217.7 & 495.3 & $1.52 \pm 0.011$ \\
& $130{ }^{\circ} \mathrm{C}$ & 39.7 & 212.8 & 471.3 & $1.95 \pm 0.014$ \\
\hline
\end{tabular}

${ }^{\text {a }}$ Values are means \pm standard deviation $(n=3)$.

capacity (WBC) of the maize flour samples were measured (Table 1). The mean particle size (d0.5) of the samples ranged between 158 and $213 \mu \mathrm{m}$, shifting to a slightly larger particle size (about 30-40 $\mu \mathrm{m}$ ) with increasing drying temperatures above $54^{\circ} \mathrm{C}$.

The increase in drying temperature led to an increase in the water binding capacity of both varieties of maize flour, up to $90{ }^{\circ} \mathrm{C}(1.51 \mathrm{~g}$ water/g DM). Above $90{ }^{\circ} \mathrm{C}$, the WBC continued to increase with differing intensity, according to the variety, to reach $1.85 \mathrm{~g}$ of water per $\mathrm{g}$ of DM for Var I and $1.95 \mathrm{~g}$ of water per $\mathrm{g}$ of DM for Var II at $130{ }^{\circ} \mathrm{C}$. This can be attributed to the partial gelatinization of maize starch that occurs during grain drying at higher temperatures (Malumba et al., 2014). The increase in WBC led to a very favourable substrate for pancreatic amylase and resulted in an altered physical structure that influenced the digestion of starch granules by gastric and pancreatic enzymes. The correlation between WBC and starch digestibility was 0.97 at 0 RPM and 0.93 at 10 RPM. The WBC of Var II was higher than that of Var I. It is possible that the higher vitreousness of Var II restrained the diffusion of water from the centre to the outer layer and thus promoted starch gelatinization.

The increase in flour particle size and WBC with the initial maize grain drying temperature probably facilitated the dispersion of the maize flour within the buffer solution, which slowed down the sedimentation of the flour particles. Under these circumstances, particles would have stayed longer in suspension and would have potentially improved contact with $\alpha$-amylases. Thus, the drying temperature may affect the dispersion of food bolus particles during digestion if no sufficient agitation regimes are applied and this may influence the hydrolysis of the flour.

Agitation may also affect the viscosity of the suspension. This is an important hydrodynamic concept, as it will influence the fluid flow behaviour (laminar versus turbulent) and consequently heat and mass transfer. The viscosity may constrain the access of enzymes toward substrates such as starch, but also decrease the rate and the extent of starch hydrolysis (Dhital, Warren, Butterworth, Ellis, \& Gidley, 2017; Singh, Kaur, \& Singh, 2013). In order to assess the effect of agitation on slurry viscosity, the apparent viscosity of the digestion solution at the intestinal step was measured. It was hypothesised that the viscosity of the solution would decrease with increasing mixing intensity and that this might improve mass transfer and consequently the digestibility of the maize flour. However, the flow behaviour was found to be similar to that of a Newtonian fluid (constant viscosity with shear rate) with very low viscosity $\left(<0.1 \mathrm{~Pa} \mathrm{~s}\right.$ at $1 \mathrm{~s}^{-1}$ ), probably because of the low solid concentration (not shown).

It is unlikely that intestinal content would behave in the same way as in this in vitro model, because of its higher solid concentration. Several studies have recorded the dry matter content of poultry digesta at between 16 and 27\% (Günal et al., 2004; Svihus et al., 1997; Takahashi et al., 2004). According to Takahashi et al. (2004), the properties of intestinal content are typical of a Herschel Bulkley fluid. In that study, the flow curve of a $25 \%$ maize flour suspension was
Table 2

Values of variables from the power law model (Ostwald De Waele) for the two maize varieties dried at $54{ }^{\circ} \mathrm{C}, 90{ }^{\circ} \mathrm{C}$ and $130{ }^{\circ} \mathrm{C}$.

\begin{tabular}{llllll}
\hline Maize variety & Drying temperature & $\mathrm{K}\left(\mathrm{Pa} . \mathrm{s}^{\mathrm{n}}\right)$ & $\mathrm{n}$ & $\mathrm{R}^{2}$ & $\mathrm{RMSE}$ \\
\hline \multirow{2}{*}{ Var I } & $54{ }^{\circ} \mathrm{C}$ & 4.70 & -0.213 & 1.000 & 0.24 \\
& $90{ }^{\circ} \mathrm{C}$ & 5.97 & -0.119 & 0.999 & 1.00 \\
& $130{ }^{\circ} \mathrm{C}$ & 7.01 & -0.190 & 0.994 & 5.79 \\
\cline { 2 - 5 } Var II & $54{ }^{\circ} \mathrm{C}$ & 5.08 & -0.216 & 1.000 & 0.38 \\
& $90{ }^{\circ} \mathrm{C}$ & 6.14 & -0.148 & 1.000 & 1.16 \\
& $130{ }^{\circ} \mathrm{C}$ & 7.17 & -0.169 & 0.997 & 4.43 \\
\hline
\end{tabular}

$\mathrm{K}$ is the consistency index $\left(\mathrm{Pa}^{\mathrm{n}} \mathrm{s}^{\mathrm{n}}\right)$; $\mathrm{n}$ is the flow behaviour index; RMSE is the root mean square of error.

recorded using a rotational rheometer.

We found that the viscosity of the maize flour samples rapidly decreased with increasing shear rate, to reach a low value $(<1 \mathrm{~Pa} \mathrm{~s})$ at 10 RPM. The consistency of these results with the data from the studies of Amerah, Ravindran, Lentle, and Thomas (2008) and Takahashi et al. (2004), measured in vivo, confirmed that these values are relevant and similar to what can be expected in the intestinal content of monogastrics. The adjustment of our collected data with a power law model (Ostwald De Wale) was made on the descending shear data between 100 and $0.1 \mathrm{~s}^{-1}$ and revealed a pseudoplastic fluid behaviour $(\mathrm{n}<1)$ (Table 2). The consistency index $(\mathrm{K})$ was found to increase with the increasing drying temperature. A strong correlation was found between WBC and $\mathrm{K}(0.98)$. As the drying temperature increased, the water binding capacity of the flour increased because of the partially gelatinized starch and this led to a higher mixture viscosity, which may have consequences for nutrient digestibility.

In our opinion, the low particle concentration used in in vitro studies does not accurately represent the fluid viscosity observed in the intestinal content of monogastrics, although it may significantly affect the process of digestion. This view is in agreement with the review of Woolnough et al. (2008), who concluded that current in vitro digestion protocols do not account for the effect of food viscosity on the rate of carbohydrate digestion.

In order to assess the progress of maize digestibility under gradual agitation, in the present study, the IVDMD at the end of the pepsinpancreatin digestion was recorded for different speeds of rotation (Fig. 3). Increasing rotational agitation significantly improved IVDMD. The increase in IVDMD was modelled with a first order equation, giving rise to several digestion kinetic parameters (Table 3 ).

The application of rotational agitation improved the dispersion of the samples inside the tubes and constrained the sedimentation, which improved the access of enzymes to the surface area, thereby promoting hydrolysis. Above $5 \mathrm{RPM}$, the digestive process seemed to reach a maximum value (asymptotic value, $\mathrm{D}_{\infty}$ ). It can be assumed that above this mixing rate, the hydrodynamic conditions were sufficient to maintain flour particles in suspension and to ensure a good homogeneity of the suspension. The increase in IVDMD under rotational agitation was less pronounced at $130{ }^{\circ} \mathrm{C}$ (Fig. $3 \mathrm{~B}$ ), probably because of the better flour dispersion in the buffer solution, as discussed previously in this study.

Warren, Butterworth, and Ellis (2012) stipulated that the adsorption and binding of the enzyme to the starch granule surface are key steps in their hydrolysis. However, while the majority of studies focus on the internal diffusion of enzymes within the matrix, the mass transfer of enzymes through the stagnant layer surrounding solid particles is also an essential factor determining the rate of hydrolysis (Gan, Allen, \& Taylor, 2003). It has been observed that the heterogeneity of the mixture inside the reactor necessitates sufficient agitation to ensure optimal contact between substrate and enzymes (Ingesson, Zacchi, Yang, Esteghlalian, \& Saddler, 2001). Adequate mixing ensures optimal mass transfer, promoting a more dynamic regime of adsorption, catalysis, 


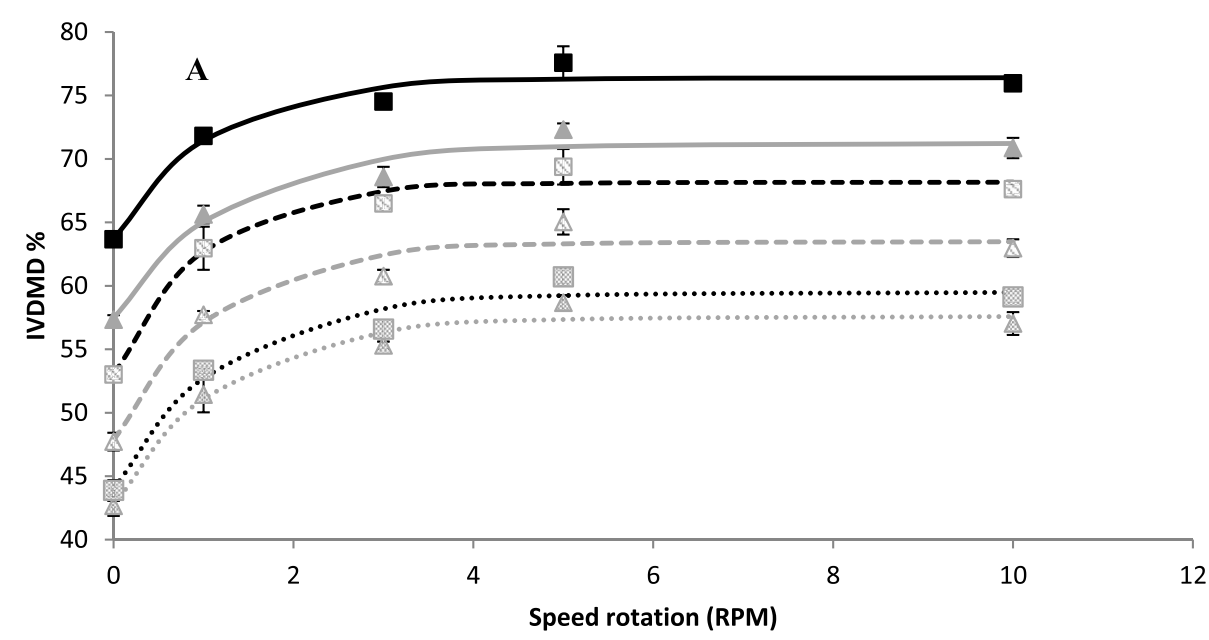

Fig. 3. Absolute (A) and relative $\left(\mathrm{D}_{\mathrm{S}}-\mathrm{D}_{0}\right)(\mathrm{B})$ in vitro dry matter digestibility of dried maize flour samples. Values are means \pm SD $(n=5)$. Experimental values (symbole); Calculated values (curve). Experimental values from Var I $54{ }^{\circ} \mathrm{C}$ (*); Experimental values from Var I $90{ }^{\circ} \mathrm{C}$ ( ); Experimental values from Var I $130{ }^{\circ} \mathrm{C}(\Delta)$; Experimental values from Var II $54{ }^{\circ} \mathrm{C}$ (四); Experimental values from Var II $90{ }^{\circ} \mathrm{C}$ (ब);

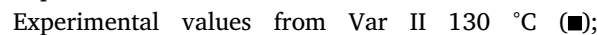
Calculated values from Var I $54{ }^{\circ} \mathrm{C}(\cdots .$.$) ; Calculated$ values from Var I $90{ }^{\circ} \mathrm{C}(--)$; Calculated values from Var I $130{ }^{\circ} \mathrm{C}(-)$; Calculated values from Var II $54{ }^{\circ} \mathrm{C}$ (....); Calculated values from Var II $90{ }^{\circ} \mathrm{C}$ (--.); Calculated values from Var II $130{ }^{\circ} \mathrm{C}(-)$.

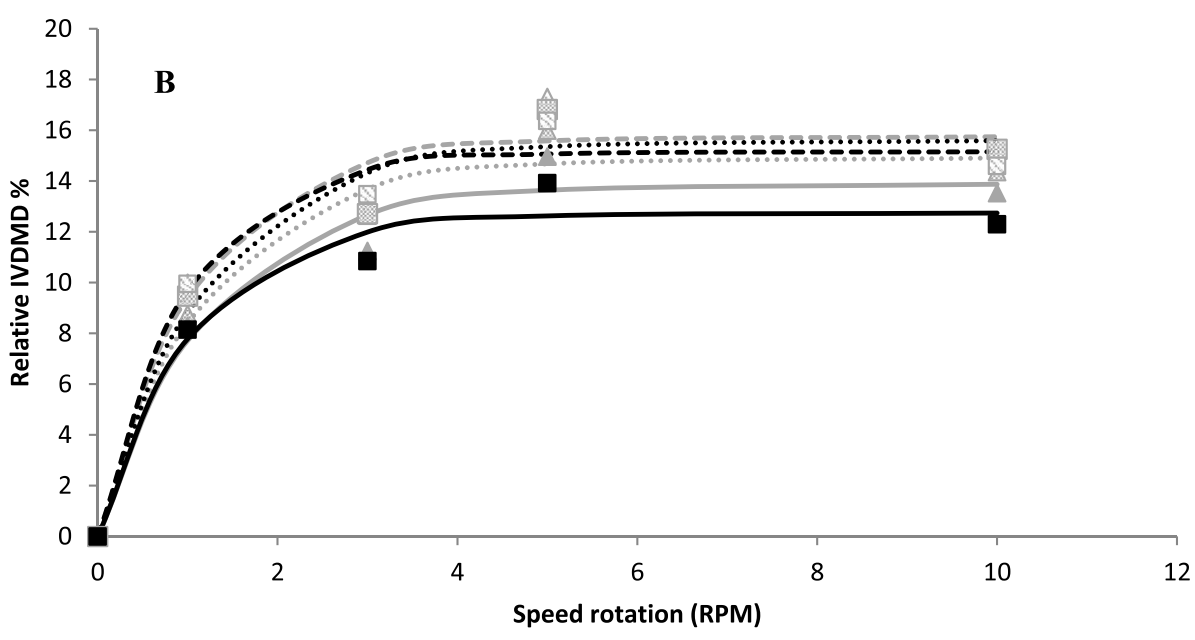

desorption, and movement to another binding site (Mussatto, Dragone, Fernandes, Milagres, \& Roberto, 2008). Moreover, sufficient agitation may reduce a high concentration of local products or substrates, which could inhibit enzyme hydrolysis (Gan et al., 2003).

It is possible to define the minimum speed of agitation required to keep solids in suspension, as defined in agitated vessels ( $\mathrm{Njs}$ ), which corresponds to the achievement of maximum dry matter digestibility $\left(D_{\infty}\right)$. This value may be obtained from the derivative of the function. In our study, we considered that this value was reached when the slope of the curves (Fig. 3 A) was less than $1 \%$, giving rise to the values $\left(\mathrm{S}_{\mathrm{m}}\right)$ shown in Table 3 . The rate constant $\left(k_{r}\right)$ is related to the ease with which the flour particles are dispersed in the solution and is negatively correlated with the minimum speed of agitation $\left(S_{m}\right)(r=-0.74)$.

Under the minimal speed of agitation $(\mathrm{Sm})$, flour digestibility is the result of factors inherent to the substrates (organization, structure, thermal history, etc.) but also of mass transfer inside the tubes, which directly affects the contact between enzymes and substrates. In order to make their results comparable, the digestibility of food and feedstuffs has to be determined, as a minimum, at the lowest mixing rate that enables samples to be maintained in suspension; otherwise, their settling behaviour will affect the digestibility of the dry matter and will impair the comparison.

\subsection{Influence of hydrodynamic conditions on the kinetic of maize flour amylolysis}

The starch digestion kinetic of dried maize measured in a shaking bath and in a rotational agitator (10 RPM) was compared, and the results are shown in Fig. 4.

It was observed that starch digestibility at the beginning of the

Table 3

Values of variables from the modified pseudo first-order model for the two maize varieties dried at $54{ }^{\circ} \mathrm{C}, 90{ }^{\circ} \mathrm{C}$ and $130{ }^{\circ} \mathrm{C}$.

\begin{tabular}{|c|c|c|c|c|c|c|c|c|}
\hline Maize variety & Drying temperature & $\mathrm{D}_{\mathrm{So}}(\%)$ & $\mathrm{D}_{\infty}(\%)$ & $\mathrm{D}_{\infty}-\mathrm{D}_{\mathrm{SO}}(\%)$ & $\mathrm{k}_{\mathrm{r}}(\mathrm{min} /$ rotation $)$ & $\mathrm{S}_{\mathrm{m}}($ rotation/min) & $\mathrm{R}^{2}$ & RMSE \\
\hline \multirow[t]{3}{*}{ Var I } & $54{ }^{\circ} \mathrm{C}$ & 42.8 & 57.6 & 14.8 & 0.823 & 5.59 & 0.990 & 0.80 \\
\hline & $90{ }^{\circ} \mathrm{C}$ & 47.9 & 63.5 & 15.6 & 0.898 & 5.13 & 0.982 & 1.13 \\
\hline & $130{ }^{\circ} \mathrm{C}$ & 57.5 & 71.2 & 13.7 & 0.799 & 5.76 & 0.985 & 0.92 \\
\hline \multirow[t]{3}{*}{ Var II } & $54{ }^{\circ} \mathrm{C}$ & 44.1 & 59.5 & 15.4 & 0.822 & 5.60 & 0.985 & 1.02 \\
\hline & $90^{\circ} \mathrm{C}$ & 53.1 & 68.2 & 15.1 & 1.015 & 4.54 & 0.991 & 0.78 \\
\hline & $130{ }^{\circ} \mathrm{C}$ & 63.7 & 76.4 & 12.7 & 0.936 & 4.92 & 0.986 & 0.81 \\
\hline
\end{tabular}

$\mathrm{D}_{\mathrm{SO}}$ is the dry matter digestibility under gentle agitation ( $\left.0 \mathrm{RPM}\right) ; \mathrm{D}_{\infty}$ is the dry matter digestibility reached at asymptotic stage; $\mathrm{k}_{\mathrm{r}}$ is the rate constant of the model; $\mathrm{S}_{\mathrm{m}}$ is the minimal speed of agitation needed to reached $\mathrm{D}_{\infty}$; RMSE is the root mean square of error. 


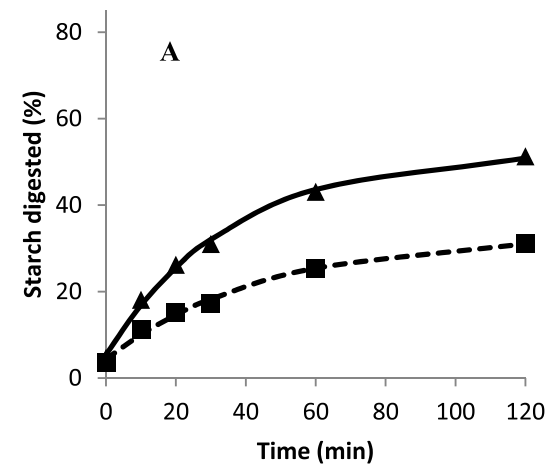

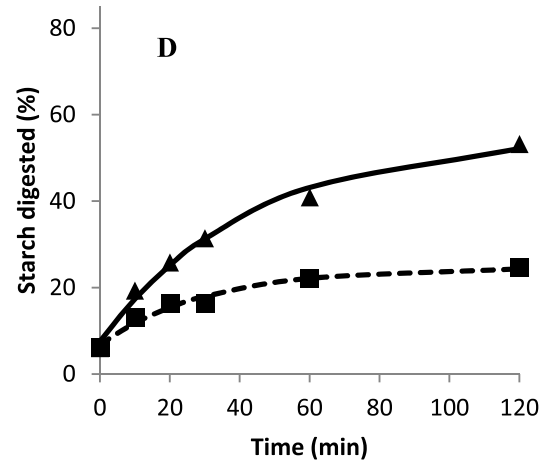

Fig. 4. Experimental (symbol) and calculated (line) digestibility curves obtained for maize flour samples under gentle agitation or at $10 \mathrm{RPM}$. Var I dried at $54{ }^{\circ} \mathrm{C}$ (A), Var I dried at $90{ }^{\circ} \mathrm{C}(\mathrm{B})$, Var I dried at $130{ }^{\circ} \mathrm{C}(\mathrm{C})$, Var II dried at $54{ }^{\circ} \mathrm{C}$ (D), Var II dried at $90{ }^{\circ} \mathrm{C}$ (E) and Var II dried at $130{ }^{\circ} \mathrm{C}$ (F). Observed values at 0 RPM ( $\square$ ), Calculated values at 0 RPM (--), Observed values at $10 \mathrm{RPM}(\boldsymbol{\Delta})$, Calculated values at 10 RPM (_).
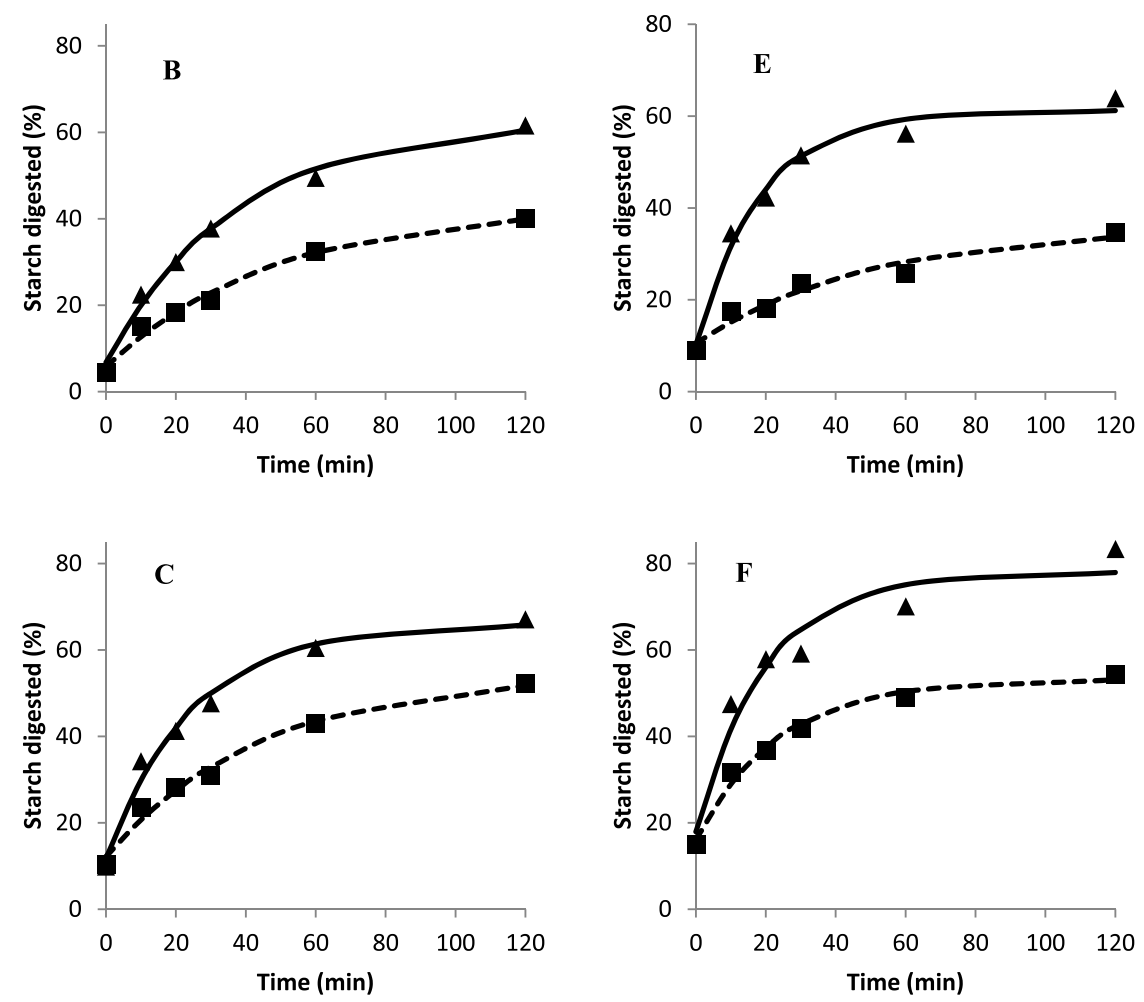

Table 4

Values of variables from the modified pseudo first-order kinetic model of starch amylomysis for the two maize varieties dried at $54{ }^{\circ} \mathrm{C}, 90{ }^{\circ} \mathrm{C}$ and $130{ }^{\circ} \mathrm{C}$.

\begin{tabular}{|c|c|c|c|c|c|c|c|}
\hline Variety & RPM & Drying temperature & $\mathrm{C}_{0}(\%)$ & $\mathrm{C}_{\infty}(\%)$ & $\mathrm{k}_{\mathrm{s}}\left(\min ^{-1}\right)$ & $\mathrm{R}^{2}$ & RMSE (\%) \\
\hline \multirow[t]{6}{*}{ Var I } & 0 & $54{ }^{\circ} \mathrm{C}$ & 4.4 & 33.1 & 0.022 & 0.997 & 0.73 \\
\hline & & $90{ }^{\circ} \mathrm{C}$ & 5.9 & 43.3 & 0.020 & 0.993 & 1.34 \\
\hline & & $130{ }^{\circ} \mathrm{C}$ & 12.3 & 54.8 & 0.022 & 0.992 & 1.65 \\
\hline & 10 & $54^{\circ} \mathrm{C}$ & 5.4 & 52.6 & 0.028 & 0.998 & 0.85 \\
\hline & & $90{ }^{\circ} \mathrm{C}$ & 6.8 & 62.7 & 0.027 & 0.996 & 1.55 \\
\hline & & $130{ }^{\circ} \mathrm{C}$ & 11.8 & 66.2 & 0.040 & 0.992 & 2.29 \\
\hline \multirow[t]{6}{*}{ Var II } & 0 & $54^{\circ} \mathrm{C}$ & 6.9 & 24.7 & 0.032 & 0.986 & 1.00 \\
\hline & & $90{ }^{\circ} \mathrm{C}$ & 10.6 & 36.1 & 0.020 & 0.974 & 1.82 \\
\hline & & $130{ }^{\circ} \mathrm{C}$ & 16.2 & 53.4 & 0.042 & 0.993 & 1.47 \\
\hline & 10 & $54{ }^{\circ} \mathrm{C}$ & 7.6 & 55.2 & 0.023 & 0.995 & 1.48 \\
\hline & & $90{ }^{\circ} \mathrm{C}$ & 10.2 & 61.3 & 0.054 & 0.992 & 2.22 \\
\hline & & $130{ }^{\circ} \mathrm{C}$ & 17.9 & 78.1 & 0.050 & 0.975 & 4.68 \\
\hline
\end{tabular}

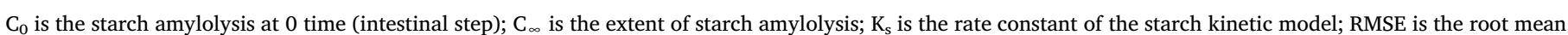
square of error.

pancreatic step $\left(\mathrm{C}_{0}\right)$ increased with the maize grain drying temperature applied, regardless of the agitation intensity or the maize variety used (Table 4). It is likely that the thermal history of the sample plays a key role in the digestion kinetic and that this may involve some preliminary hydrolysis or solubilization of the maize flour dry matter. Starch gelatinization implies the leaching out of the starch granules and solubilization of low molecular weight amylose (Gallant, Bouchet, \& Baldwin, 1997). As heating of maize grain induces partial gelatinization of starch 
beyond $80{ }^{\circ} \mathrm{C}$ (Malumba et al., 2010), the suspension of flour in the liquid during an in vitro procedure releases soluble amylose molecules. The release of these soluble polysaccharides is enhanced by the disruption by pepsin of the protein matrix surrounding the starch granules in endosperm flour particles. In this way, the soluble amylose molecules contribute to the increase in glucose at the beginning of the intestinal stage of digestion.

It was observed that as the drying temperature increased from 54 to $130{ }^{\circ} \mathrm{C}$, the total extent of amylolysis $\left(\mathrm{C}_{\infty}\right)$ increased from $33.1 \%$ to $54.8 \%$ for Var I and from $24.7 \%$ to $53.4 \%$ for Var II under gentle agitation (0 RPM). These results are in agreement with the increase in starch digestibility observed previously, related to the transformation of starch during the drying process. Compared to the kinetic recorded using a mixing rate of $10 \mathrm{RPM}$, the extent of starch digestibility at 0 RPM was lower (Table 4). It is likely that the use of adequate agitation (10 RPM) improved the contact between substrates and enzymes and consequently the extent of starch amylolysis.

Besides indicating the potential starch degradability, the starch hydrolysis kinetic gives important information about the rate of glucose release over time and the associated mechanism. This is particularly relevant for human health and animal production. Estimation of the glycaemic index of food products allows for the management of the postprandial rise in blood glucose. This is especially relevant for people suffering from type 2 diabetes or with abnormalities in blood glucose regulation (Lovegrove et al., 2017). In animal production, the rate of starch hydrolysis is important because a continuous supply of glucose throughout the day results in a gradual insulin release and brings the energy required for protein deposition (Weurding, Veldman, Veen, van der Aar, \& Verstegen, 2001). In the present study, the rate at which amylolysis occurred $\left(\mathrm{k}_{\mathrm{s}}\right)$ was found to increase at $10 \mathrm{RPM}$. While no clear trends were found under gentle agitation, the rate constant increased with increasing drying temperatures at 10 RPM (Table 4).

According to Dhital et al. (2017), starch digestion is limited by two major factors. The first factor relates to the barriers that may impair the accessibility of enzymes to the starch; such barriers include the protein matrix, cell walls, size of starch granules, the presence of surface pores and digesta viscosity. The second factor is linked to the structure of the starch granules, including the amylose/amylopectin ratio, A or B type structure, starch structure in relation to processing and other aspects.

Contact between substrate and enzymes is a prerequisite for amylolysis. This may account for the first group of rate-limiting factors, as described by Dhital et al. (2017), reducing the accessibility of enzymes to starch granules. Agitation promotes the mass transfer of the enzymes through the stagnant layer surrounding solid particles within the solution and thus a more dynamic regime of adsorption, catalysis, desorption, and movement to another binding site. While at 0 RPM, the starch digestion kinetic was predominantly governed by the limited contact between enzymes and substrates (high heterogeneity, high concentration of local products), at 10 RPM, this barrier was removed and the rate of amylolysis was mainly governed by the structural features of the starch granules, depending on the drying process undergone by the maize grain. This is attested by the higher correlation between the WBC and rate constant at 10 RPM (0.675) compared with 0 RPM (0.383).

These results showed that hydrodynamic conditions affected the extent and the rate of starch hydrolysis, and that the main rate-limiting starch digestion mechanism involved differed depending on the mixing intensity. Application of different hydrodynamic regimes during in vitro digestion of feedstuff or food may contribute to various hydrolysis kinetics, which may have consequences for glycaemic response interpretation.

\section{Conclusion}

In comparison with a gentle agitation, high mixing rates applied during the in vitro digestion protocol greatly improved the digestibility of the maize flour dry matter and starch, as well as the amylolysis rate of the samples. These increases were mainly explained by the restriction of flour particle sedimentation. Thermal history suffered by maize flour particle (drying procedure) influenced the particles mixing rate during in vitro digestion procedures as well as their buffer binding capacity and sedimentation rates, that probably affected the digestibility indexes measured. This may threatens the comparison of starchy feedstuffs with different thermal history. Consequently, it is useful to define the minimum value of agitation required to provide adequate hydrodynamic conditions for maintaining flour particles in suspension and for allowing a safe comparison between food and feedstuff digestibility. Since most of in vitro procedures commonly used in the laboratories do not accurately reproduce the food bolus agitation process occurring in the animal's gastrointestinal tract and are not standardized, they can lead to errors of assessment and make it difficult to compare the digestibility of starchy materials. Mixing procedures need to be optimized and standardized in order to allow for a reliable comparison of in vitro digestibility of different feedstuffs and to improve the predictive quality of in vitro digestion models.

\section{Author contributions section}

\section{Study conception and design}

Huart François.

Malumba Paul.

\section{Acquisition of data}

Huart François. Peclers Nathalie.

\section{Analysis and interpretation of data}

Huart François.

Peclers Nathalie.

Malumba Paul.

Beckers Yves.

\section{Drafting of manuscript}

Huart François.

Bera François.

Malumba Paul.

Beckers Yves.

\section{Critical revision}

Huart François.

Malumba Paul.

Beckers Yves.

Bera François.

\section{Funding}

This study was supported by the "Direction Génerale Opérationnelle de l'Agriculture, des Ressources Naturelles et de l'Environnement" of the Walloon government through the project MAISECVOL (grant number D31-1364).

\section{Declaration of competing interest}

The authors declare no competing financial interest. 


\section{Acknowledgement}

The authors are grateful to Romain Thomas of the University of Liège, Gembloux Agro Bio-Tech for his technical support.

\section{References}

Alegría, A., Garcia-Llatas, G., \& Cilla, A. (2015). Static digestion models: General introduction. In K. Verhoeckx,, P. Cotter,, I. López-Expósito,, C. Kleiveland,, T. Lea,, \& A. Mackie, (Eds.). The impact of food bioactives on health (pp. 3-12). Cham: Springer International Publishing. https://doi.org/10.1007/978-3-319-16104-4_1.

Amerah, A. M., Ravindran, V., Lentle, R. G., \& Thomas, D. G. (2008). Influence of feed particle size on the performance, energy utilization, digestive tract development, and digesta parameters of broiler starters fed wheat- and corn-based diets. Poultry Science, 87(11), 2320-2328. https://doi.org/10.3382/ps.2008-00149.

AOAC (1990). Official methods of analysis (15th ed.). Arlington, VA: Association of official analytical chemists.

Berti, C., Riso, P., Monti, L. D., \& Porrini, M. (2004). In vitro starch digestibility and in vivo glucose response of gluten-free foods and their gluten counterparts. European Journal of Nutrition, 43(4), 198-204. https://doi oro/10.1007/s00394-004-0459-1.

Bohn, T., Carriere, F., Day, L., Deglaire, A., Egger, L., Freitas, D., et al. (2018). Correlation between in vitro and in vivo data on food digestion. What can we predict with static in vitro digestion models ? Critical Reviews in Food Science and Nutrition, 58(13), 1-23. https://doi.org/10.1080/10408398.2017.1315362.

Boisen, S., \& Fernández, J. A. (1997). Prediction of the total tract digestibility of energy in feedstuffs and pig diets by in vitro analyses. Animal Feed Science and Technology, 68(3-4), 277-286. https://doi.org/10.1016/S0377-8401(97)00058-8.

Brand-Miller, J., \& Holt, S. (2004). Testing the glycaemic index of foods : In vivo, not in vitro. European Journal of Clinical Nutrition, 58, 700-701. https://doi.org/10.1038/sj. ejcn.1601856.

Chauvierre, C., Labarre, D., Couvreur, P., \& Vauthier, C. (2004). A new approach for the characterization of insoluble amphiphilic copolymers based on their emulsifying properties. Colloid \& Polymer Science, 282(10), 1097-1104. https://doi.org/10.1007/ s00396-003-1040-9.

Dhital, S., Warren, F. J., Butterworth, P. J., Ellis, P. R., \& Gidley, M. J. (2017) Mechanisms of starch digestion by $\alpha$-amylase-structural basis for kinetic properties. Critical Reviews in Food Science and Nutrition, 57(5), 875-892. https://doi.org/10. 1080/10408398.2014.922043.

Gallant, D. J., Bouchet, B., \& Baldwin, P. M. (1997). Microscopy of starch: Evidence of a new level of granule organization. Carbohydrate Polymers, 32(3-4), 177-191. https:// doi.org/10.1016/S0144-8617(97)00008-8.

Gan, Q., Allen, S. J., \& Taylor, G. (2003). Kinetic dynamics in heterogeneous enzymatic hydrolysis of cellulose: An overview, an experimental study and mathematical modelling. Process Biochemistry, 38(7), 1003-1018. https://doi.org/10.1016/S00329592(02)00220-0.

Goni, I., Garcia-Alonso, A., \& Saura-Calixto, F. (1997). A starch hydrolysis procedure to estimate glycemic index. Nutrition Research, 17(3), 427-437. https://doi.org/10. 1016/S0271-5317(97)00010-9.

Günal, M., Yaşar, S., \& Forbes, J. M. (2004). Performance and some digesta parameters of broiler chickens given low or high viscosity wheat-based diets with or without enzyme supplementation. Turkish Journal of Veterinary and Animal Sciences, 28(2), 323-327. https://doi.org/10.13140/RG.2.1.1575.7840.

Huart, F., Malumba, P., Odjo, S., Al-Izzi, W., Béra, F., \& Beckers, Y. (2018). In vitro and in vivo assessment of the effect of initial moisture content and drying temperature on the feeding value of maize grain. British Poultry Science, 59(4), 452-462. https://doi. org/10.1080/00071668.2018.1477253.

Ingesson, H., Zacchi, G., Yang, B., Esteghlalian, A. R., \& Saddler, J. N. (2001). The effect of shaking regime on the rate and extent of enzymatic hydrolysis of cellulose. Journal of Biotechnology, 88(2), 177-182. https://doi.org/10.1016/S0168-1656(01)00273-5.

Janas, S., Boutry, S., Malumba, P., Vander Elst, L., \& Béra, F. (2010). Modelling dehydration and quality degradation of maize during fluidized-bed drying. Journal of Food Engineering, 100(3), 527-534. https://doi.org/10.1016/j.jfoodeng.2010.05.001.

Kong, F., \& Singh, R. P. (2010). A human gastric simulator (HGS) to study food digestion in human stomach. Journal of Food Science, 75(9), E627-E635. https://doi.org/10. $1111 / \mathrm{j} .1750-3841.2010 .01856 . x$
Lovegrove, A., Edwards, C. H., De Noni, I., Patel, H., El, S. N., Grassby, T., et al. (2017) Role of polysaccharides in food, digestion, and health. Critical Reviews in Food Science and Nutrition, 57(2), 237-253. https://doi.org/10.1080/10408398.2014.939263.

Malumba, P., Janas, S., Roiseux, O., Sinnaeve, G., Masimango, T., Sindic, M., et al. (2010). Comparative study of the effect of drying temperatures and heat-moisture treatment on the physicochemical and functional properties of corn starch. Carbohydrate Polymers, 79(3), 633-641. https://doi.org/10.1016/j.carbpol.2009.09. 013.

Malumba, P., Odjo, S., Boudry, C., Danthine, S., Bindelle, J., Beckers, Y., et al. (2014). Physicochemical characterization and in vitro assessment of the nutritive value of starch yield from corn dried at different temperatures. Starch - Stärke, 66(7-8), 738-748. https://doi.org/10.1002/star.201400012.

Mengual, O. (1999). TURBISCAN MA 2000: Multiple light scattering measurement for concentrated emulsion and suspension instability analysis. Talanta, 50(2), 445-456. https://doi.org/10.1016/S0039-9140(99)00129-0.

Minekus, M., Alminger, M., Alvito, P., Ballance, S., Bohn, T., Bourlieu, C., et al. (2014). A standardised static in vitro digestion method suitable for food - an international consensus. Food \& Function, 5, 1113-1124. https://doi.org/10.1039/c3fo60702j.

Mussatto, S. I., Dragone, G., Fernandes, M., Milagres, A. M. F., \& Roberto, I. C. (2008). The effect of agitation speed, enzyme loading and substrate concentration on enzymatic hydrolysis of cellulose from brewer's spent grain. Cellulose, 15(5), 711-721. https://doi.org/10.1007/s10570-008-9215-7.

Odjo, S., Béra, F., Beckers, Y., Foucart, G., \& Malumba, P. (2018). Influence of variety, harvesting date and drying temperature on the composition and the in vitro digestibility of corn grain. Journal of Cereal Science, 79, 218-225. https://doi.org/10.1016/ j.jcs.2017.10.008.

Odjo, S., Béra, F., Jacquet, N., Richel, A., \& Malumba, P. (2016). Characterization of saccharides released during an in vitro pepsin-pancreatin digestion of corn flour using HPAEC-PAD. Starch - Stärke, 68(7-8), 691-699. https://doi.org/10.1002/star. 201500281.

Rozan, P., Lamghari, R., Linder, M., Villaume, C., Fanni, J., Parmentier, M., et al. (1997) In vivo and in vitro digestibility of soybean, lupine, and rapeseed meal proteins after various technological processes. Journal of Agricultural and Food Chemistry, 45(5), 1762-1769. https://doi.org/10.1021/jf960723v.

Singh, J., Kaur, L., \& Singh, H. (2013). Food microstructure and starch digestion. In J. Henry (Ed.). Advances in food and nutrition research (pp. 137-179). Burlington: Academic Press. https://doi.org/10.1016/B978-0-12-416555-7.00004-7.

Svihus, B., Herstad, O., Newman, C. W., \& Newman, R. K. (1997). Comparison of performance and intestinal characteristics of broiler chickens fed on diets containing whole, rolled or ground barley. British Poultry Science, 38(5), 524-529. https://doi. org $/ 10.1080 / 00071669708418032$

Takahashi, T., Goto, M., \& Sakata, T. (2004). Viscoelastic properties of the small intestinal and caecal contents of the chicken. British Journal of Nutrition, 91(6), 867-872. https://doi.org/10.1079/BJN20041129.

Tervilä-Wilo, A., Parkkonen, T., Morgan, A., Poutanen, K., Heikkinen, P., \& Autio, K. (1996). In vitro digestion of wheat microstructure with xylanase and cellulase from trichoderma reesei. Journal of Cereal Science, 24(3), 215-225. https://doi.org/10. $1006 /$ jcrs.

Van Soest, P. J., Robertson, J. B., \& Lewis, B. A. (1991). Methods for dietary fiber, neutral detergent fiber, and nonstarch polysaccharides in relation to animal nutrition. Journal of Dairy Science, 74(10), 3583-3597. https://doi.org/10.3168/jds.S0022-0302(91) 78551-2.

Van Wey, A. S., \& Shorten, P. R. (2014). Mathematical models of food degradation in the human stomach. In M. Boland, M. Golding, \& H. Singh (Eds.). Food structures, digestion and health (pp. 245-272). Academic Press. https://doi.org/10.1016/B978-0-12404610-8.00009-8.

Warren, F. J., Butterworth, P. J., \& Ellis, P. R. (2012). Studies of the effect of maltose on the direct binding of porcine pancreatic $\alpha$-amylase to maize starch. Carbohydrate Research, 358, 67-71. https://doi.org/10.1016/j.carres.2012.07.004.

Weurding, R. E., Veldman, A., Veen, W. A. G., van der Aar, P. J., \& Verstegen, M. W. A. (2001). Starch digestion rate in the small intestine of broiler chickens differs among feedstuffs. Journal of Nutrition, 131(9), 2329-2335. https://doi.org/10.1093/jn/131. 9.2329 .

Woolnough, J. W., Monro, J. A., Brennan, C. S., \& Bird, A. R. (2008). Simulating human carbohydrate digestion in vitro : A review of methods and the need for standardisation. International Journal of Food Science and Technology, 43(12), 2245-2256. https://doi.org/10.1111/j.1365-2621.2008.01862.x. 